Provided for non-commercial research and educational use only. Not for reproduction or distribution or commercial use.

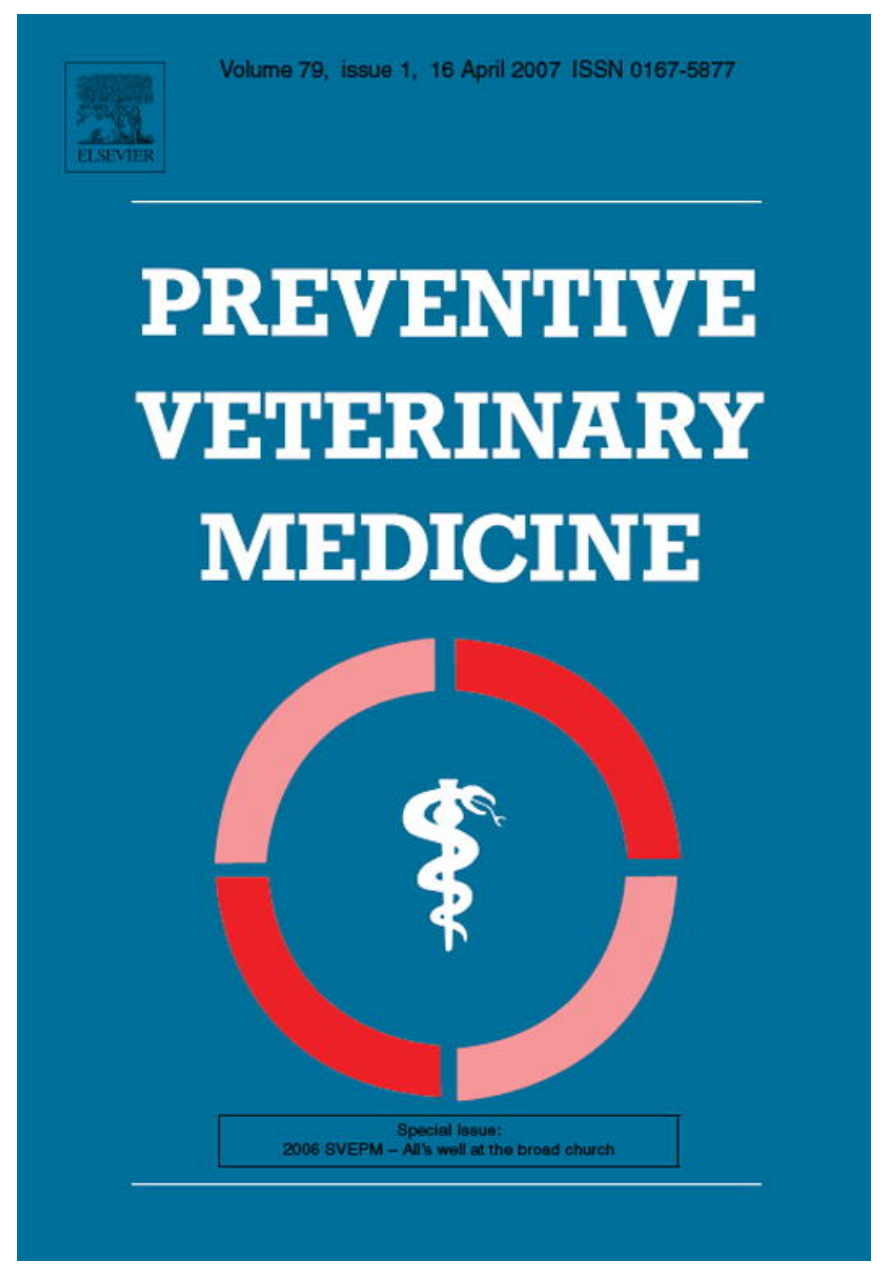

This article was originally published in a journal published by Elsevier, and the attached copy is provided by Elsevier for the author's benefit and for the benefit of the author's institution, for non-commercial research and educational use including without limitation use in instruction at your institution, sending it to specific colleagues that you know, and providing a copy to your institution's administrator.

All other uses, reproduction and distribution, including without limitation commercial reprints, selling or licensing copies or access,

or posting on open internet sites, your personal or institution's website or repository, are prohibited. For exceptions, permission may be sought for such use through Elsevier's permissions site at: 


\title{
Assessing the effect of interventions on the risk of cattle and sheep carrying Escherichia coli O157:H7 to the abattoir using a stochastic model
}

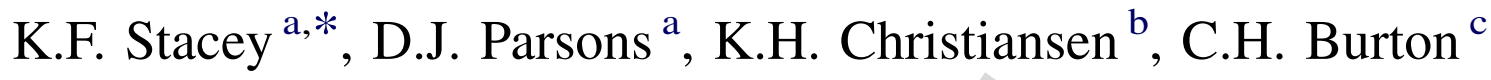

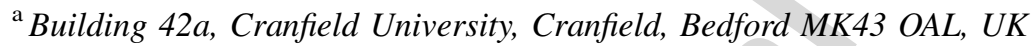 \\ ${ }^{\mathrm{b}}$ Veterinary Laboratories Agency, New Haw, Addlestone, Surrey KT15 3NB, UK \\ ${ }^{\mathrm{c}}$ Cemagref Rennes, 17 Avenue de Cucillé, CS 64427, 35044 Rennes, France
}

\begin{abstract}
Escherichia coli $\mathrm{O} 157: \mathrm{H} 7$ persists in being a threat to food safety. The mechanisms behind the spread of E. coli $\mathrm{O} 157: \mathrm{H} 7$ on the farm are complex and poorly understood. The objective of this study was to apply a Monte Carlo model, constructed to simulate the propagation of E. coli $\mathrm{O} 157: \mathrm{H} 7$ in cattle and sheep on the farm, to both test the effect of different interventions on the risk of animals carrying E. coli $\mathrm{O} 157: \mathrm{H} 7$ to the abattoir and to develop understanding of the underlying processes, including the identification of areas that could benefit from further research. An overview of the model including key assumptions is given.

The output statistics from batches of 100 runs of the model were collected. From the model output, a cumulative frequency distribution of the prevalence and specific shedding level for the groups of cattle or sheep being sent to the abattoir were generated. Stochastic dominance was used to compare the results of the model outputs.

Using the shorthand that "risk" means the likelihood of carrying E. coli O157:H7 to the abattoir, key conclusions from the study included: mixing sheep and cattle increases the risk in both groups; merging groups of animals of the same species into larger groups increases the risk substantially; increasing stocking density increases the risk independently of group size; decreasing the group size decreases the $E$. coli $0157: \mathrm{H} 7$ prevalence independently of stocking density; a very high level of barn hygiene reduces the risk; a shorter time between spreading farmyard manure and grazing and an increased background level of E. coli $\mathrm{O} 157: \mathrm{H} 7$ in the model increases the risk. The background level could be influenced by the presence of wild animals carrying the organism.
\end{abstract}

\footnotetext{
* Corresponding author. Tel.: +44 1234750111.

E-mail address: k.stacey@cranfield.ac.uk (K.F. Stacey).
} 
The parameters to which the model is most sensitive are those related to transmission from grass and enclosures to animals, pathogen survival on grass, in slurry and in barns and contact between animals. (C) 2006 Elsevier B.V. All rights reserved.

Keywords: Escherichia coli; E. coli O157:H7; Sheep; Cattle; Monte Carlo; Risk; Simulation

\section{Introduction}

Escherichia coli $\mathrm{O} 157: \mathrm{H} 7$ was first identified as a human pathogen in 1982 in two outbreaks of gastrointestinal illness associated with the consumption of hamburgers from a fast food chain in the United States (Riley et al., 1983). E. coli O157:H7 may cause severe disease and death in humans. In an outbreak of E. coli O157:H7 infection in Scotland in 1996, as many as 496 people may have been affected and 20 people died from eating cold cooked meats probably cross-contaminated with E. coli $0157: \mathrm{H} 7$ in raw meat in a butcher's shop (Ahmed and Donaghy, 1998). Anxiety in Great Britain has been further heightened by two recent outbreaks of E. coli O157:H7 in South Wales in September 2005 (117 cases) and in the Brecon area in November 2005 (12 cases). Cattle, and possibly sheep, are currently recognised as the principal reservoirs responsible for the proliferation of E. coli O157:H7 on farms (Wallace, 1999). However, there has also been isolation of the organism from other farm animal species, such as goats, deer and chickens.

This paper gives an overview of a model, constructed to simulate the propagation of $E$. coli $\mathrm{O} 157: \mathrm{H} 7$ in cattle and sheep on the farm. The model is used to test the effect of different farm management interventions on the risk of animals carrying E. coli O157:H7 to the abattoir and to develop understanding of the underlying processes. Further details of the model may be found in Parsons et al. (2002).

\section{Materials and methods}

A stochastic simulation model was developed within which risks can be calculated and the consequences of actions explored. A literature review and information gathered from farm visits were used to inform the construction of the model. A consultation workshop with experts from outside the project was held to review the proposed structure and concepts (Parsons, 2001). The construction of the model was based largely on data from Great Britain. The model consists of two parts:

- a deterministic simulation of the interactions between animals, feed, enclosures and waste on cattle and sheep farms to study the impact of different factors (described in Section 2.1);

- a stochastic simulation of the epidemiology of E. coli O157:H7 to study the likelihood that animals for the abattoir are carrying E. coli O157:H7 (described in Section 2.2).

Each run of the simulation resulted in one possible outcome of the system with values for prevalence and distributions of specific shedding level (CFU/g) of E. coli O157:H7 
throughout the year for each group of animals. By performing batches of runs, distributions for the model outputs were obtained. The impact of changes to the management of the farm, or to the underlying assumptions, were examined.

\subsection{Farm system part of the model}

The farm system part of the model provided a general, flexible structure to describe factors likely to influence the transmission of $E$. coli $\mathrm{O} 157: \mathrm{H} 7 \mathrm{such}$ as the movements of animals, contact between animals and movement of waste. A single model flexible enough to represent almost any conventional type of cattle or sheep farm was developed.

In the model, a group of animals is a collection of individuals of similar age that are normally kept together and treated alike. Two or more groups may share the same enclosure at some times, and be separated at other times. A resource was defined as any potential reservoir or vector for $\mathrm{O} 157: \mathrm{H} 7$, such as a field, a building, a slurry store or a feed trough. Resources will often be shared by several groups of animal, so they may be a route for cross-infection between animals (within and between groups). Four types of resources are distinguished in the model: enclosures (further divided into fields, yards and barns), waste stores, feed troughs and water troughs. Table 1 gives the attributes of the groups and resources.

The specification of an individual farm is defined by input files: the number of fields, yards, barns and the number of animals in each age group on the farm; the characteristics of each enclosure, each group of animals, storage of waste; movement of waste; birth; death and movement of animals within and on and off the farm. Meteorological data and the parameters of the model, such as the decay rate of E. coli O157:H7 in different environments are also given in an input file.

To be able to compare the effects of different interventions, the parts of the farm that could be controlled or partially controlled by the farm manager are deterministic. For example, the movement of animals from one enclosure to another, but also the week in which animals are born or die on the farm, are determined by input files.

Table 1

Group and resource attributes used in simulation model for Escherichia coli in cattle and sheep

\begin{tabular}{lllll}
\hline Group & Resources & & & \\
\cline { 2 - 4 } & Enclosure & Water trough & Feed trough & Waste store \\
\hline Name & Name & Volume & Type of feed & Mass of \\
Type (sheep, cattle) & Type & $\begin{array}{l}\text { Cleaning } \\
\text { interval }\end{array}$ & and hay) & \\
Age & Number of groups & & \\
Age of weaning & List of groups & & \\
Enclosure & Area & & \\
Number of animals & Area grazed & & \\
Weight of one animal & Area of silage & & \\
Feed intake per animal & Frequency of & & \\
Water intake per animal & cleaning & & \\
Faeces production per animal & & & \\
Proportion of each type of feed & & & \\
\hline
\end{tabular}


A single run of the model simulates a period of at least 1 year using a fixed time step of 1 week. At the start of a run a set of entities (groups and resources) are created. Simple models are used for the time-dependent attributes, with coefficients that depend on the type of animals. Weight is linearly dependent on age, up to a maximum for the species. Dry matter feed intake is a power law function of weight. Water intake is proportional to feed intake. Faeces production is linearly dependent on feed intake. Other variables are updated through the linkage between groups and resources, for example, the volume of slurry in a waste store depends on the rate of production of all the animal groups in the enclosures feeding it.

Animals leaving the farm for sale as livestock, culling or the abattoir are handled by moving them into special groups which are emptied at the end of the time step. This allows relevant information on the animals leaving the farm to be collated. The farm model is always set up to simulate a steady state, that is, with identical numbers and ages of animals in each group at the same time each year (after 12 months the model is back to the initial state).

\subsection{Epidemiological part of the model}

The epidemiological part of the model simulates the carriage and transmission of E. coli O157:H7 within and between groups of animals and resources (Tables 2 and 3). The entities described in the farm model were given additional attributes related to $E$. coli O157:H7 that quantified the infection of groups or contamination of resources. Both the prevalence and the level of shedding are described by the number of animals with a specific shedding rate (concentration of E. coli $\mathrm{O} 157: \mathrm{H} 7$ in faeces) in each of a series of logarithmic ranges: $0,0-10, \ldots, 10^{7}$ to $10^{8} \mathrm{CFU} / \mathrm{g}$ (used to calculate shedding rates). For each resource, the growth or decay of E. coli $0157: \mathrm{H} 7$ and transfers to and from other entities were considered. The model works with groups of animals with respect to farm management and on an individual basis with respect to transmission of E. coli O157:H7.

The epidemiological part of the model is a stochastic simulation: many of the transitions in the model are described by probability distributions. Some of the processes in the model are temperature dependent. A set of 30 years weather data from Birmingham was gathered and reduced to 30 years of weekly mean temperatures. For each week in a run of the simulation, one of the 30 weekly mean temperatures for that week is randomly selected. The weekly temperatures are thus treated as independent random variables distributed about the long-term mean.

Each run simulated 10 years with the farm model in a steady-state and the results were sampled from the last year only. A period of 10 years was found to be sufficient to stabilise the output so that there was little trend over time of either increasing or decreasing prevalence or mean shedding rate.

\subsubsection{Infection of animals and the dose-response relationship}

Experimental and field studies indicate that cattle do not develop effective immunity to colonisation by E. coli O157:H7 (Shere et al., 1998; Sanderson et al., 1999). No immunity was assumed and the same transition matrix is used for naïve and previously infected animals, and animals cannot be reinfected whilst shedding.

The total dose of E. coli O157:H7 received by an animal from all the routes discussed above is calculated. The probability of infection is calculated according to the dose- 
Table 2

Modelling of the decay and growth of E. coli $\mathrm{O} 157: \mathrm{H} 7$ in resources and animal groups and the contamination of resources

\begin{tabular}{|c|c|}
\hline Process and resources & Description \\
\hline \multicolumn{2}{|l|}{ Decay and growth } \\
\hline $\begin{array}{l}\text { Decay in resources } \\
\text { except feed troughs }\end{array}$ & $\begin{array}{l}\text { Temperature dependent exponential decay with higher temperatures leading } \\
\text { to faster decay. Coefficients, derived from literature, differ between resources } \\
\text { (Wang et al., 1996; Kudva et al., 1998; Rice and Johnson, 2000; } \\
\text { Nicholson et al., 2000) }\end{array}$ \\
\hline Decay in feed troughs & $\begin{array}{l}\text { Assumes no survival on the timescale of the model (because the farm } \\
\text { manager or the animals will clear the trough weekly) }\end{array}$ \\
\hline $\begin{array}{l}\text { Growth/decay in } \\
\text { animal groups }\end{array}$ & $\begin{array}{l}\text { On infection, transition to a variable peak shedding rate (for cattle } 10^{6} \text { to } \\
10^{8} \mathrm{CFU} / \mathrm{g} \text { ). The specific shedding rate decays exponentially with a fixed } \\
\text { probability of moving from one shedding level to the next. Infection duration } \\
\text { has a mode of } 5 \text { weeks and survival beyond } 8 \text { weeks is very rare } \\
\text { (Sanderson et al., 1999; Buchko et al., 2000). For sheep the peak shedding } \\
\text { is lower and the initial decline is slightly slower }\end{array}$ \\
\hline \multicolumn{2}{|l|}{ Contamination } \\
\hline Enclosure & $\begin{array}{l}\text { Initial condition }(C F U) \text { : Zero at start; cleaning a yard or barn sets the load to zero } \\
\text { Rate of change ( } C F U / \text { day): Mean specific shedding rate multiplied by the } \\
\text { faeces production of each group in the enclosure }\end{array}$ \\
\hline Slurry store & $\begin{array}{l}\text { Initial condition }(C F U) \text { : When emptied load is set to zero } \\
\text { Rate of change (CFU/day): Homogeneous mixing of the contents of the store } \\
\text { with the incoming slurry }\end{array}$ \\
\hline Water trough & $\begin{array}{l}\text { Initial condition }(C F U) \text { : When cleaned the load is set to zero } \\
\text { Rate of change }(C F U / d a y) \text { : Proportional to the sum of the products of mean } \\
\text { specific shedding rate and water consumption rate of each of the groups using it }\end{array}$ \\
\hline Feed trough & $\begin{array}{l}\text { Load }(\mathrm{CFU}) \text { is proportional to the sum of the products of mean specific shedding } \\
\text { rate and consumption of feed from the trough for the groups using it }\end{array}$ \\
\hline
\end{tabular}

CFU: colony forming unit.

Table 3

Modelling the dose of E. coli $\mathrm{O} 157: \mathrm{H} 7$ from resources to animals and between animals

\begin{tabular}{|c|c|}
\hline Resource & Dose received by each animal (CFU) \\
\hline ards and barns & $\begin{array}{l}\text { Proportional to the product of dry matter feed intake }(\mathrm{g}) \text { and concentration of } \\
\text { E. coli } \mathrm{O} 157: \mathrm{H} 7 \text { in enclosure }\left(\mathrm{CFU} / \mathrm{m}^{2}\right)\end{array}$ \\
\hline Fields & $\begin{array}{l}\text { Proportional to product of grass consumption (g/day) and concentration of } \\
\text { E. coli } \mathrm{O} 157: \mathrm{H} 7\left(\mathrm{CFU} / \mathrm{m}^{2}\right)\end{array}$ \\
\hline Vater & $\begin{array}{l}\text { Proportional to the product of the water intake (g/day) and the load in } \\
\text { the trough }(\mathrm{CFU} / \mathrm{g})\end{array}$ \\
\hline Feed trough & $\begin{array}{l}\text { Equal to the product of the concentrate feed intake (g/day) and the load in } \\
\text { the trough }(\mathrm{CFU} / \mathrm{g})\end{array}$ \\
\hline Background & $\begin{array}{l}\text { Proportional to product of dry matter feed intake and background level }\left(\mathrm{CFU} / \mathrm{m}^{2}\right) \text {. } \\
\text { This represents exposure to other sources such as wild birds and animals }\end{array}$ \\
\hline $\begin{array}{l}\text { Transmission between } \\
\text { animals sharing } \\
\text { an enclosure }\end{array}$ & $\begin{array}{l}\text { Proportional to the contact animal's specific shedding rate }(\mathrm{CFU} / \mathrm{g}) \text {. Each } \\
\text { day each animal makes a fixed number of contacts with randomly selected } \\
\text { animals in the same enclosure }\end{array}$ \\
\hline
\end{tabular}

CFU: colony forming unit. 
response relationship, which was modelled as a Beta-Poisson distribution (Brown et al., 1998). The parameters were adjusted to give infection rates similar to those reported in the literature. An increase in the probability of infection with dose, and a decrease with age of the host has been demonstrated (Cray and Moon, 1995; Cornick et al., 2000). The dose is standardised by dividing by the host mass. It was assumed that animals are immune until weaning (Paiba et al., 2003).

\subsection{Parameterisation and calibration}

Wherever possible, data from experiments or observational studies at the level of individual processes were used to set parameter values in the model. There were also useful data on features such as the survival of E. coli $\mathrm{O} 157: \mathrm{H} 7$ in slurry, soil, etc., from which reasonable extrapolations could be made to other conditions. There were limited data from which approximate estimates could be made for other parameters, such as the transition parameters (for infection) and the dose-response relationship.

The remaining parameters were set by considering the overall behaviour of the model in comparison with farm observations. In all of the routes of transmission, such as from the feed trough or from grazing, there is at least one parameter where there is great uncertainty. These parameters were adjusted collectively to give prevalence levels that approximated to those found in the literature (Paiba et al., 2003).

In order to achieve a sufficiently low prevalence in sheep, the parameter relating dose to the product of grass consumption and the concentration of E. coli $\mathrm{O} 157: \mathrm{H} 7$ was lower than for cattle. New infections on farms that have been clear for some months are uncommon, so the background level of infectivity was set to give typically two to four infections per year. Insufficient evidence existed for a seasonal pattern of prevalences to be used.

\subsection{Farm system specifications}

Input files were constructed for four different types of farm: a beef breeder-finisher farm, a beef finisher farm, a sheep farm and a mixed beef and sheep farm. In each of these base cases the interval between slurry spreading and grazing was 4 weeks; slurry/manure was cleared from the barns every 2 weeks and the water troughs were cleaned every 5 weeks. The animal to animal contact rate was five per day. Modifications to these farms were constructed to test the effect of interventions. The farm system specifications are given in Table 4. The mixed beef and sheep farm specifications considered the effects on the prevalence of $E$. coli $\mathrm{O} 157: \mathrm{H} 7$ in cattle and sheep in the case where all the grazing was shared compared with the same stock kept in separate fields. Inter-species contact was assumed to be as likely as intra-species when co-grazing. Unless otherwise specified other management variables were the same as for the single species farms.

\subsection{Method of analysis of output from simulation model}

\subsubsection{Sensitivity analysis}

A sensitivity analysis was undertaken to identify the parameters for which the output was most sensitive. The beef breeder-finisher farm was used as it contained all aspects of 
Table 4

Farm system specifications

\begin{tabular}{|c|c|c|c|}
\hline Farm & Herd/Flock & Enclosures & Manure/slurry management \\
\hline $\begin{array}{l}\text { Beef breeder- } \\
\text { finisher farm }\end{array}$ & $\begin{array}{l}\text { Ten heifers and } 40 \text { cows, calving in week } 40 \\
\text { (1 October) for } 5 \text { years; replacements bought } \\
\text { in week } 40 \text { at } 86 \text { weeks; fattening } 50 \text { calves } \\
\text { per year on an } 18 \text {-month system, slaughtering } \\
\text { older group in week } 22\end{array}$ & $\begin{array}{l}\text { Seventy-five hectares of grass and three barns; } \\
\text { the breeders and the two groups of calves grazed } \\
\text { and housed separately; in spring } 45 \text { ha reserved for } \\
\text { silage, reduced to } 30 \text { ha on week } 24 \text { (first cut) and } \\
\text { all grazed from week } 31 \text { (second cut); grazing from } \\
30 \text { April to } 17 \text { September }\end{array}$ & $\begin{array}{l}\text { Sixty percent of total } \\
\text { spread on all grassland } \\
\text { on week 14; remainder } \\
\text { spread on weeks } 22 \text { and } 25\end{array}$ \\
\hline Beef fattener farm & $\begin{array}{l}\text { Group of } 50 \text { calves bought aged } 9 \text { weeks in } \\
\text { week } 48 \text { ( } 26 \text { November) and slaughtering at } \\
\text { age } 79 \text { weeks ( } 18 \text { months) in week } 14\end{array}$ & $\begin{array}{l}\text { Twenty-five hectares of grass and two barns } \\
\text { (young and year-old calved housed separately); } \\
\text { in spring } 15 \text { ha reserved for silage, reduced to } \\
10 \text { ha on week } 24 \text { (first cut) and all grazed from } \\
\text { week } 31 \text { (second cut); grazing from } 30 \text { April to } \\
17 \text { September }\end{array}$ & $\begin{array}{l}\text { Sixty percent of total } \\
\text { spread on all grassland } \\
\text { on week } 14 \text {; remainder } \\
\text { spread in week } 25 \text { on } \\
\text { silage aftermath }\end{array}$ \\
\hline Sheep farm & $\begin{array}{l}\text { Hundred ewes, producing an average of } 1.5 \\
\text { lambs per year for } 5 \text { years. Lambing in week } \\
13 \text {; old ewes culled in week } 21 \text {; in-lamb ewes } \\
\text { bought in week } 1 \text {; slaughtering lambs in week } 40\end{array}$ & $\begin{array}{l}\text { Ten hectare field; ewes in one barn from } \\
\text { weeks } 12 \text { to } 14\end{array}$ & $\begin{array}{l}\text { Spread on a } \\
\text { separate field }\end{array}$ \\
\hline $\begin{array}{l}\text { Mixed beef and } \\
\text { sheep farm }\end{array}$ & $\begin{array}{l}\text { As for beef fattener farm and sheep farm, } \\
\text { respectively }\end{array}$ & $\begin{array}{l}\text { Single } 30 \text { ha field; separate barns. } \\
\text { Alternative: field of } 10 \text { ha for sheep; } \\
\text { separate barns }\end{array}$ & $\begin{array}{l}\text { Spread on non- } \\
\text { grazing field }\end{array}$ \\
\hline
\end{tabular}


the model. For the base case, all the parameters were set to their default values and three batches of 100 runs of the model were performed. Each of the parameters selected for analysis was then increased and decreased individually, and two batches of 100 runs were performed for each setting. Parameters related to transmission rates or concentrations were normally multiplied and divided by 10 (i.e. a one log unit change). The decay rate exponents are temperature dependent and typically lie in the range 0.2-0.9; the size of the changes used in the sensitivity analysis was 0.1 . The animal to animal contact rate was normally five per day and values of 1 and 20 were tested.

In each case the changes were assessed by considering the magnitude of the change in the mean prevalence (averaged over 200 runs) from the standard mean prevalence (averaged over 300 runs) at four points in the year: weeks 9, 22, 35 and 45. Animals are housed during weeks 9 and 45 and graze during the weeks 22 and 35. Splitting each trial into batches allowed the variability resulting from the model to be considered.

\subsubsection{Effect of interventions on simulated farms}

First order stochastic dominance (Hardaker et al., 2004) was used to test the effect of different interventions on the risk of different levels of prevalence and specific shedding level in cattle and sheep being sent to the abattoir, from each type of farm.

To assess first order stochastic dominance (hereafter dominance), the data were plotted as cumulative frequency distributions (CFDs), by sorting the data in order of increasing magnitude of the variable of interest and plotting the order in the list, giving the frequency against the variable. Dominance was determined through the comparison of two CFDs for the same variable before and after an intervention. The curve that is wholly to the left or above the other is said to dominate, because it is clearly the preferable outcome. For each farm several possible interventions were tested to identify those having a substantial effect. Two batches of 100 runs were performed for each of the first two farms to ensure that the results were reproducible. It was found that the differences between the two batches of 100 runs used for the study of the first two farms were small, so one batch of 100 runs was used for each option from this point on.

In the farm interventions, note that in each case when the slurry spreading date was changed, the grazing date was not; instead there was a change in the interval between spreading and grazing. When the farm size was changed, the number of groups was kept constant; the numbers of animals and enclosure areas were changed in proportion; so this was considering the effect of group size independently of stocking density. Similarly the effect of reducing stocking density was tested independently from the farm size; stocking density was reduced by reducing the area of grazing and keeping the number of animals constant.

\section{Results}

\subsection{Validation and calibration}

It was possible to calibrate the model so that it produced prevalence values close to those reported in the literature (Paiba et al., 2003). In a recent survey of dairy and beef farms in 
England and Wales, Paiba et al. (2003) found that the overall animal prevalence (proportion of animals shedding) was $4.7 \%$ across all farm types, and $10.5 \%$ in fattener herds, which was consistent with several other surveys reported in the literature. From the model output, the mean animal prevalence for the beef fattener herd was $14 \%$, a little higher than that found by Paiba et al. (2003). The results for other farm types for cattle were reasonably consistent with the observations. However, Paiba et al. (2003) also reported that the herd prevalence was $44 \%$ and the within herd prevalence was $10.2 \%$. The corresponding values for the abattoir group in the model were $21 \%$ and $44 \%$.

Comparable recent data for sheep were fewer. Small et al. (2002) found E. coli O157 in $7.2 \%$ of cattle lairages and $2.2 \%$ of sheep lairages, and also on $28.8 \%$ of cattle hides and $5.5 \%$ of sheep. A tentative extrapolation would then suggest that animal prevalences should be around one-fifth to one-quarter of those in cattle, i.e. about $1-2.5 \%$. The full range of results shown later was $0.25-5.8 \%$, with the base cases around $1 \%$. The model generated herd prevalence was $25 \%$ and a within herd prevalence of $2.9 \%$, which was probably a more realistic combination than for cattle.

E. coli $\mathrm{O} 157: \mathrm{H} 7$ was present at some time in almost all the simulated farms in the later years (i.e. not as a result of initial conditions). Consistent with observational data from the literature (for instance, Mechie et al., 1997), in the simulated farms cattle and sheep often had more than one episode of E. coli O157:H7 colonisation and shedding; the shedding level and duration were highly variable amongst individuals.

\subsection{Sensitivity analysis}

The standard mean prevalences at the four selected weeks were $14.8 \%, 16.5 \%, 13.6 \%$ and $11.3 \%$. The mean absolute differences between sets were $1.9 \%, 2.0 \%, 1.5 \%$ and $1.6 \%$, respectively. Several parameters increased or decreased the mean prevalence by more than twice the mean absolute difference between batches, for the same farm specification and for $\geq 1$ of the four sampling points in the year. These more sensitive parameters were: those influencing the decay rates for grassland, barns and slurry stores; transmission from the enclosure and from grass; animal to animal contact rate; faeces dose per contact between animals; age at which animals are first susceptible to infection. Less sensitive parameters were: water decay rate; contamination of water from animals; transmission from feed.

It is clear that, for the sizes of changes made, most of the parameters relating to transmission of $E$. coli $\mathrm{O} 157: \mathrm{H} 7$ to the animals had larger effects than the decay rates, especially the one related to grazing. Of the decay rates, the one for grassland had the largest effect. Changing the age of weaning, so that calves were susceptible from birth resulted in a substantial increase in prevalence. Contrary to expectations, increasing the barn decay rate, increased the prevalence.

\subsection{Effect of interventions on simulated farms}

Tables 5-7 show the results of different interventions on the beef breeder-finisher farm, the beef fattener farm and the sheep farm on prevalence and shedding of E. coli O157:H7 in animals destined for slaughter. These interventions are ranked according to their impact on 
Table 5

Ranking of management factors on beef breeder-finisher farm, by effect on prevalence of E. coli O157:H7 shedding in cattle being sent to the abattoir (first week of June)

\begin{tabular}{|c|c|c|c|}
\hline Intervention & $\begin{array}{l}\text { Mean animal } \\
\text { prevalence }(\%)\end{array}$ & $\begin{array}{l}\text { Rank by } \\
\text { shedding rate }\end{array}$ & $\begin{array}{l}\text { Mean specific } \\
\text { shedding }(\mathrm{CFU} / \mathrm{g})\end{array}$ \\
\hline Barn clean interval 1 week & 1.4 & 1 & 970 \\
\hline Farm size $-50 \%$ & 3.9 & 2 & 6,500 \\
\hline Background level $-50 \%$ & 4.4 & 2 & 4,500 \\
\hline Barn clean interval 11 weeks & 6.9 & 4 & 7,400 \\
\hline Contact rate $=1$ per day & 6.8 & 4 & 5,200 \\
\hline Spreading to grazing interval $=4$ weeks & 8.1 & 6 & 5,100 \\
\hline Base $(0 \% \text { purchased stock prevalence })^{\mathrm{a}}$ & 9.6 & 7 & 13,000 \\
\hline Barn clean interval 5 weeks & 9.7 & 7 & 9,600 \\
\hline Background level $+50 \%$ & 13 & 9 & 13,000 \\
\hline Contact rate $=20$ per day & 14 & 9 & 14,000 \\
\hline Farm size $+50 \%$ & 15 & 9 & 16,000 \\
\hline Spreading to grazing interval $=6$ weeks & 14 & 9 & 13,000 \\
\hline Prevalence in purchased stock $5 \%$ & 21 & 13 & 19,000 \\
\hline All animals mixed in summer & 49 & 14 & 51,000 \\
\hline
\end{tabular}

An item in bold dominates the one below it; an item in italics does not achieve first-order dominance, but is dominant over most of the range. CFU: colony forming unit.

a The base case to which the interventions relate.

prevalence in the abattoir group. The higher up a table an intervention is, the lower the risk of animals entering the abattoir with $E$. coli $\mathrm{O} 157: \mathrm{H} 7$. The mean animal prevalence values are also shown. Where there is first order dominance, the mean of the dominant item must be smaller.

Table 6

Ranking of management factors on beef fattener farm, by effect on prevalence of E. coli O157:H7 shedding in cattle being sent to the abattoir (first week of April)

\begin{tabular}{|c|c|c|c|}
\hline Intervention & $\begin{array}{l}\text { Mean animal } \\
\text { prevalence }(\%)\end{array}$ & $\begin{array}{l}\text { Rank by } \\
\text { shedding rate }\end{array}$ & $\begin{array}{l}\text { Mean specific } \\
\text { shedding }(\mathrm{CFU} / \mathrm{g})\end{array}$ \\
\hline Barn clean interval 1 week & 1.9 & 1 & 410 \\
\hline Farm size $-\mathbf{5 0 \%}$ & 4.9 & 2 & 5,900 \\
\hline Prevalence in purchased stock $0 \%$ & 7.8 & 2 & 6,300 \\
\hline Contact rate $=1$ per day & 14 & 4 & 12,000 \\
\hline Spreading to grazing interval $=2$ weeks & 15 & 5 & 16,000 \\
\hline Background level $-50 \%$ & 15 & 6 & 13,000 \\
\hline Base $(5 \% \text { purchased stock prevalence })^{\mathrm{a}}$ & 14 & 6 & 11,000 \\
\hline Spreading to grazing interval $=6$ weeks & 17 & 6 & 13,000 \\
\hline Barn cleaning interval 5 weeks & 22 & 6 & 24,000 \\
\hline Contact rate $=20$ per day & 24 & 10 & 20,000 \\
\hline Background level $+\mathbf{5 0 \%}$ & 24 & 11 & 21,000 \\
\hline Barn cleaning interval 11 weeks & 32 & 12 & 27,000 \\
\hline Farm size $+\mathbf{5 0} \%$ & 46 & 13 & 41,000 \\
\hline All animals mixed in winter & 51 & 14 & 52,000 \\
\hline
\end{tabular}

An item in bold dominates the one below it; an item in italics does not achieve first-order dominance, but is dominant over most of the range. CFU: colony forming unit.

a The base case to which the interventions relate. 
Table 7

Ranking of management factors on sheep farm, by effect on prevalence of E. coli $\mathrm{O} 157: \mathrm{H} 7$ shedding in lambs being sent to the abattoir (first week of October)

\begin{tabular}{|c|c|c|c|}
\hline Intervention & $\begin{array}{l}\text { Mean animal } \\
\text { prevalence }(\%)\end{array}$ & $\begin{array}{l}\text { Rank by } \\
\text { shedding rate }\end{array}$ & $\begin{array}{l}\text { Mean specific } \\
\text { shedding }(\mathrm{CFU} / \mathrm{g})\end{array}$ \\
\hline Stocking density $-25 \%$ & 0.25 & 1 & 25 \\
\hline Farm size $-\mathbf{5 0 \%}$ & 0.43 & 1 & 200 \\
\hline Contact rate $=1$ per day & 0.93 & 3 & 210 \\
\hline Base $(2 \% \text { purchased stock prevalence })^{\mathrm{a}}$ & 0.88 & 3 & 370 \\
\hline Zero percentage of purchased stock prevalence & 1.2 & 3 & 240 \\
\hline Farm size $+\mathbf{5 0 \%}$ & 1.3 & 3 & 360 \\
\hline Stocking density $+25 \%$ & 2.8 & 7 & 1000 \\
\hline Contact rate $=20$ per day & 5.8 & 7 & 1200 \\
\hline
\end{tabular}

An item in bold dominates the one below it. CFU: colony forming unit.

a The base case to which the interventions relate.

\subsubsection{Breeder-finisher farm and beef fattener farm}

There were 13 interventions tested on the breeder-finisher farm (Table 5) and the beef fattener farm (Table 6) relative to the base case for each farm. The interventions tested on these farms were comparable, but a couple of differences should be noted. The option of mixing the animals in one field in summer was used in the breeder-finisher farm, but in the beef fattener farm it was more appropriate to use a single barn in winter to test the effect of mixing.

The relative size and direction of the effects were similar across the two farms with some differences in ordering. Increasing the farm size had a strong detrimental impact. Mixing the groups during summer grazing or in winter housing increased and reducing the contact rate decreased prevalence and shedding of $E$. coli $\mathrm{O} 157: \mathrm{H} 7 \mathrm{in}$ animals destined for slaughter. Reducing the interval between spreading slurry and grazing the land from 4 to 2 weeks increased prevalence and shedding of E. coli $\mathrm{O} 157: \mathrm{H} 7$ in animals destined for slaughter, whereas increasing it to 6 weeks had only a small negative effect. Reducing the background level of E. coli $\mathrm{O} 157: \mathrm{H} 7$, which could reflect general hygiene or carriage by vermin and other animals, decreased prevalence and shedding of E. coli O157:H7 in animals destined for slaughter.

Very frequent barn cleaning decreased prevalence and shedding of E. coli O157:H7 in animals destined for slaughter on both farms, although the latter assumes that all E. coli O157:H7 are removed, which is highly unlikely in practice. Finally, assuming a 5\% E. coli O157:H7 prevalence in the stock purchased each year strongly increased the presence of $E$. coli $\mathrm{O} 157: \mathrm{H} 7$ on both farms.

\subsubsection{Sheep farm}

There were six interventions tested on the sheep farm (Table 7). The effect of changing stocking density was tested only on this farm. Consistent with the cattle farms, increasing farm size, stocking density and contact rate produced marked increases in the prevalence and the converse measures tended to reduce it. The effect of changes in contact rate is greater than on the cattle farms. Contrary to expectations reducing incoming prevalence had a slightly detrimental effect. 
Table 8

Effect of mixed grazing on the prevalence of shedding of E. coli $\mathrm{O} 157: \mathrm{H} 7$ in cattle and lambs being sent to the abattoir (cattle: first week of April; lambs: first week of October)

\begin{tabular}{llcc}
\hline Group & Mixing & Mean animal prevalence $(\%)$ & Mean specific shedding $(\mathrm{CFU} / \mathrm{g})$ \\
\hline Lambs & Fully mixed & 5 & 580 \\
Lambs & Separate grazing & 0.9 & 140 \\
Cattle & Fully mixed & 22 & 13,000 \\
Cattle & Separate grazing & 10 & 13,000 \\
\hline
\end{tabular}

\subsubsection{Mixed beef and sheep farm}

Table 8 shows the effects on mean prevalence and shedding in both calves and lambs on a mixed beef and sheep farm. Mixing with cattle caused a substantial increase in mean prevalence and shedding amongst the lambs. The CFDs for the lambs showed that separate grazing was dominant in both variables. Mixing also caused a substantial increase in mean prevalence amongst the calves, though the effect on mean shedding was fairly small. Examination of the CFDs for the cattle showed that separate grazing was dominant when measured by prevalence, but a few farms with high mean shedding rates meant that the curves for shedding rate crossed and explained the small effect on the mean.

\section{Discussion}

In a simulation study of this type, where the system being simulated is complex and good data are sparse, care is needed when interpreting the results, which necessarily reflect the assumptions built into the model. The parameters with a high level of uncertainty were adjusted to give reasonable relative doses on the basis of very little information. Therefore, the model cannot be used to determine which transmission route, for instance from grazing or from barns, is most important; more data would be required for it to be able to do this. Furthermore, the underestimation of the within herd prevalence compared to the herd prevalence of the model is likely to have led to an overestimation of the effect of interventions affecting the herd prevalence (background level of E. coli O157:H7 and prevalence of purchased stock) and an underestimation of those affecting the within herd prevalence (the remaining interventions). The tests used to generate the results and the interpretation of these results reported here were chosen to be robust, so that changes in uncertain parameter values would not have a major effect on the conclusions.

The strongly detrimental and consistent effect of increasing the farm size may be because there is a lower probability of $E$. coli $\mathrm{O} 157: \mathrm{H} 7$ entering and being maintained in a smaller population, than in a larger population. A similar argument may be applied to the detrimental effect of mixing groups during summer grazing or in winter housing.

Contact rate was included as one of the interventions, as well as in the sensitivity analysis, since it may be influenced by the farm management, for example by reducing the stocking rate. However, there is still much to learn about what affects the contact rate between farm animals, the contact structure and the amount of faecal material transferred at each contact. The effect of contact rate is greater in sheep farms than on cattle farms, 
possibly due to the dynamics of infection that lead to a greater within herd prevalence compared to herd prevalence in sheep farms compared to beef farms.

The detrimental effect of mixing species is greater than would be expected from an increase in stocking rate alone, which was relatively small in this comparison. The increase in risk in both cattle and sheep may be due to the different dynamics of propagation in each of the two species helping to sustain infection in the other group. More research is needed to understand these dynamics better.

The three results where the direction of change was opposite to expectations cannot be easily explained without further investigation, but they are probably the result of the intrinsic variability of the model.

\section{Conclusions}

The main conclusions from the study, are that the likelihood that animals going to the abattoir are carrying E. coli $\mathrm{O} 157: \mathrm{H} 7$ is increased by mixing cattle and sheep and merging groups of the same species into larger groups. Similarly increasing the farm or group size, independently of stocking density and increasing stocking density, independently of group size, increases the risk. A very high level of barn hygiene reduces the risk; but the difference between intermediate and poor levels is small, except when a barn is used all year round. Constructing and testing models is part of an iterative process and often raises pertinent questions stimulating further research in modelling and in observational and experimental studies. The parameters to which the model is most sensitive (and hence those that it is most important to quantify) are the ones related to: transmission from grass and enclosures to animals; contact between animals; pathogen survival on grass, in slurry and in barns.

\section{Acknowledgements}

The authors gratefully acknowledge the financial support of Defra project OZ0708 and the contribution from farmers who participated in the study.

\section{References}

Ahmed, S., Donaghy, M., 1998. An outbreak of Escherichia coli O157:H7 in Central Scotland. In: Kaper, J.B., O'Brien, A.D. (Eds.), Escherichia coli O157:H7 and Other Shiga Toxin-Producing E. coli Strains. American Society for Microbiology, Washington, DC, pp. 59-65.

Brown, M.H., Davies, K.W., Billon, C.M.P., Adair, C., McClure, P.J., 1998. Quantitative microbiological risk assessment: principles applied to determining the comparative risk of salmonellosis from chicken products. J. Food Prot. 61 (11), 1446-1453.

Buchko, S.J., Holley, R.A., Olson, W.O., Gannon, V.P.J., Veira, D.M., 2000. The effect of different grain diets on fecal shedding of Escherichia coli O157:H7 by steers. J. Food Prot. 63, 1467-1474.

Cornick, N.A., Booher, S.L., Casey, T.A., Moon, H.W., 2000. Persistent colonization of sheep by Escherichia coli O157:H7 and other E. coli pathotypes. Appl. Environ. Microbiol. 66, 4926-4934. 
Cray Jr., W.C., Moon, H.W., 1995. Experimental infection of calves and adult cattle with Escherichia coli O157:H7. Appl. Environ. Microbiol. 61, 1586-1590.

Hardaker, J.B., Huirne, R.B.M., Anderson, J.R., Lien, G., 2004. Coping with Risk in Agriculture. CABI Publishing, Wallingford, UK, pp. 140-156.

Kudva, I.T., Blanch, K., Hovde, C.J., 1998. Analysis of Escherichia coli O157:H7 survival in ovine or bovine manure and manure slurry. Appl. Environ. Microbiol. 64, 3166-3174.

Mechie, S.C., Chapman, P.A., Siddons, C.A., 1997. A 15 months study of Escherichia coli O157:H7 in a dairy herd. Epidemiol. Infect. 118, 17-25.

Nicholson, F.A., Hutchinson, M.L., Smith, K.A., Keevil, C.W., Chambers, B.J., Moore, A., 2000. A study on farm manure applications to agricultural land and an assessment of the risks of pathogen transfer into the food chain. Report to Ministry of Agriculture, Fisheries and Food, Project Number FS2526. Unpublished.

Paiba, G.A., Wilesmith, J.W., Evans, S.J., Pascoe, S.J.S., Smith, R.P., Kidd, S.A., Ryan, J.B.M., McLaren, I.M., Chappell, S.A., Willshaw, G.A., Cheasty, T., French, N.P., Jones, T.W., Buchanan, H.F., Challoner, D.J., Colloff, A.D., Cranwell, M.P., Daniel, R.G., Davies, I.H., Duff, J.P., Hogg, R.A., Kirby, F.D., Millar, M.F., Monies, R.J., Nicholls, M.J., Payne, J.H., 2003. The prevalence of faecal excretion of verocytotoxigenic Escherichia coli (E. coli O157:H7) in cattle in England and Wales. Vet. Rec. 153, 347-353.

Parsons, D.J. (Ed.), 2001. E. coli O157:H7 in cattle and sheep from farm to abattoir-an expert review workshop. Workshop held at Silsoe Research Institute, May 31, 2001 for MAFF Project Code OZ0708, Silsoe Research Institute, Silsoe, p. 24.

Parsons, D.J., Christiansen, K.H., Stacey, K.F. Burton, C.H., 2002. A systems analysis methodology to elucidate and evaluate critical control points for E. coli $\mathrm{O} 157: \mathrm{H} 7$ in cattle and sheep from farm to abattoir. Final Report on Defra Project Number OZ0708 (available from http://www2.defra.gov.uk/research/Project_Data/). Unpublished.

Rice, E.W., Johnson, C.H., 2000. Survival of Escherichia coli O157:H7 in dairy cattle drinking water. J. Dairy Sci. 83, 2021-2023.

Riley, L.W., Remis, R.S., Helgerson, S.D., McGee, H.B., Wells, J.G., Davis, B.R., Hebert, R.J., Olcott, E.S., Johnson, L.M., Hargrett, N.T., Blake, P.A., Cohen, M.L., 1983. Hemorrhagic colitis associated with a rare Escherichia coli serotype. N. Engl. J. Med. 308, 681-685.

Sanderson, M.W., Besser, T.E., Gay, J.M., Gay, C.C., Hancock, D.D., 1999. Fecal Escherichia coli O157:H7 shedding patterns of orally inoculated calves. Vet. Microbiol. 69, 199-205.

Shere, J.A., Bartlett, K.J., Kaspar, C.W., 1998. Longitudinal study of Escherichia coli O157:H7 dissemination on four dairy farms in Wisconsin. Appl. Environ. Microbiol. 64, 1390-1399.

Small, A., Reid, C.-A., Avery, S.M., Karabasil, N., Crowley, C., Buncic, S., 2002. Potential for the spread of Escherichia coli O157, Salmonella and Campylobacter in the lairage environment at abattoirs. J. Food Prot. 65 (6), 931-936.

Wallace, J.S., 1999. The ecological cycle of Escherichia coli O157:H7. In: Stewart, C.S., Flint, H.J. (Eds.), Escherichia coli $\mathrm{O} 157$ in Farm Animals. CABI Publishing, Wallingford, UK, pp. 195-223.

Wang, G., Zhao, T., Doyle, M.P., 1996. Fate of enterohemorrhagic Escherichia coli O157:H7 in bovine feces. Appl. Environ. Microbiol. 62, 2567-2570. 